\title{
PRINZ, Friedrich, Deutschlands Frühgeschichte. Kelten, Römer und Germanen
}

\section{Bruno Judic}

\section{OpenEdition}

\author{
Journals
}

Édition électronique

URL : http://journals.openedition.org/ifha/997

DOI : $10.4000 /$ ifha. 997

ISSN : 2198-8943

Éditeur

IFRA - Institut franco-allemand (sciences historiques et sociales)

Référence électronique

Bruno Judic, «PRINZ, Friedrich, Deutschlands Frühgeschichte. Kelten, Römer und Germanen », Revue de I'IFHA [En ligne], Date de recension, mis en ligne le 01 janvier 2004, consulté le 22 septembre 2020. URL : http://journals.openedition.org/ifha/997 ; DOI : https://doi.org/10.4000/ifha.997

Ce document a été généré automatiquement le 22 septembre 2020

(CIFHA 


\title{
PRINZ, Friedrich, Deutschlands Frühgeschichte. Kelten, Römer und Germanen
}

\author{
Bruno Judic
}

Il s'agit d'un manuel de synthèse sur le très haut Moyen Âge " allemand », puisque ce livre fut d'abord publié comme premier volume du Manuel d'Histoire Allemande de Gebhardt. La période considérée va des origines au début du " règne » de Charles Martel (714).

L'ouvrage est divisé en cinq sections : fondements, les Francs envahisseurs et fondateurs d'un royaume, l'Église comme pont entre l'Antiquité romaine tardive et le Moyen Âge européen, la société européenne du haut Moyen Âge : éléments antiques et formes nouvelles, rupture culturelle et transfert culturel. Dans les fondements, l'auteur rappelle quelques données géographiques essentielles de l'espace de la Mitteleuropa, il évoque ensuite les Celtes qui ont fortement marqué de leur présence cet espace et sont bien attestés à la fois par les auteurs antiques grecs et latins et par les données archéologiques. Il décrit l'émergence des peuples germaniques en relation avec l'expansion de l'empire romain (en rappelant, bien sûr, l'importance du livre de Tacite pour la connaissance de ces anciens Germains). Il insiste enfin sur les structures de l'empire romain tardif qui marquèrent profondément certaines régions au sud du Danube et à l'ouest du Rhin. La deuxième section est consacrée à l'émergence du royaume franc. Cette section, plus narrative, évoque nécessairement Clovis puis les partages entre les héritiers mérovingiens. De manière très logique, on insiste sur le règne de Dagobert marqué par l'expansion à l'est du Rhin. On insiste aussi sur les relations du monde franc avec certains peuples, les Alamans, les Bavarois, les Thuringiens, les Saxons et les Frisons, ces relations allant parfois jusqu'à l'intégration au royaume franc. Un chapitre est justement consacré au monde slave occidental. Enfin l'essor des Pippinides (ou Précarolingiens) est souligné avec la croissance du pouvoir de Pépin II. La troisième section est consacrée à l'Église. Les évêchés antiques ont subi un déclin dans la période des invasions. Néanmoins ils retrouvent leur rôle dans le royaume franc. Le monachisme, sur des racines antiques, connaît un renouveau avec 
l'action de missionnaires irlandais et anglo-saxons. La mission chrétienne est un élément puissant d'unité culturelle européenne. Cette section est d'autant plus appréciable que l'auteur s'arrête en 714 ; c'est dire que l'accent porte sur Colomban et Willibrord plutôt que sur Pirmin et Boniface. La quatrième section aborde l'histoire sociale. Il s'agit d'examiner d'abord la place respective de la royauté et de l'aristocratie ; celle-ci tire son origine aussi bien du monde romain antique que de l'aristocratie franque. On étudie ensuite la question des Stämme. Les groupes sociaux et leurs rapports (seigneuries ecclésiastiques et laïques, pauvres et esclaves) permettent d'aborder la question de la famille : le droit familial apparaît aussi bien marqué par l'héritage romain que par l'héritage germanique. Enfin sont présentées les formes anciennes, les ruptures et les continuités dans l'existence des villes et dans l'activité économiques. La dernière section est consacrée à la culture. Les traditions antiques païennes et chrétiennes ont exercé de profondes influences. Les modèles chrétiens sont à la fois en rupture et en continuité avec l'Antiquité. L'Église dispose d'un réseau de communication très étendu marqué par la circulation des manuscrits. Tout cela est perceptible dans les formes de production littéraire et artistique.

On appréciera les larges synthèses offertes par ce livre et la volonté d'inscrire l'histoire « allemande » dans un concept européen fortement construit et pensé.

Bruno JUDIC (Université de Tours) 